\title{
The Emergence of Symbolic Algebra as a Shift in Predominant Models
}

\author{
Albrecht Heeffer
}

(C) Springer Science+Business Media B.V. 2008

\begin{abstract}
Historians of science find it difficult to pinpoint to an exact period in which symbolic algebra came into existence. This can be explained partly because the historical process leading to this breakthrough in mathematics has been a complex and diffuse one. On the other hand, it might also be the case that in the early twentieth century, historians of mathematics over emphasized the achievements in algebraic procedures and underestimated the conceptual changes leading to symbolic algebra. This paper attempts to provide a more precise setting for the historical context in which this decisive step to symbolic reasoning took place. For that purpose we will consider algebraic problem solving as model-based reasoning and symbolic representation as a model. This allows us to characterize the emergence of symbolic algebra as a shift from a geometrical to a symbolic mode of representation. The use of the symbolic as a model will be situated in the context of mercantilism where merchant activity of exchange has led to reciprocal relations between money and wealth.
\end{abstract}

Keywords Symbolism $\cdot$ Algebra $\cdot$ Model-based reasoning

\section{Introduction}

The broader scope of our research project is to understand how mathematical concepts come into existence and change during their historical development. More specifically we are interested in the role of symbolic reasoning in mathematical concept formation. For this purpose the emergence of symbolic algebra during the sixteenth century is the major development in the history of mathematics. Before that period, arithmetic and algebra were performed rhetorically. ${ }^{1}$ Modern mathematics from the seventeenth century onwards was mostly

1 The term 'rhetorical algebra' was coined by Nesselmann (1842), who distinguished rhetorical, syncopated and symbolic algebra. We challenge this distinction and use the term here in its general sense of verbal argumentation.

A. Heeffer $(\bowtie)$

Center for Logic and Philosophy of Science, Ghent University, Ghent, Belgium

e-mail: albrecht.heeffer@ugent.be 
symbolic. How did this fundamental shift in reasoning take place and why precisely during the sixteenth century? We will not be able to answer these questions completely on this occasion. However, a scenario will be provided which offers a possible explanation. Considering algebra as model-based reasoning, the MBR framework allows us to view the emergence of symbolic algebra as a shift between models predominant in their historical context. Let us define algebra, consistent with recent interpretations by Mahoney (1980) and Høyrup (2002, 278-281), as follows: 'An analytical problem-solving method for arithmetical problems using an unknown quantity represented by an abstract entity.' Much has been written about the precise meaning of analysis, but given the historical context it is appropriate to adopt the seventeenth-century interpretation of Arnauld (1996, 239). Arnauld's treatment of analysis and synthesis was derived from Descartes and had an important influence on seventeenth-century philosophers of nature such as Newton and Leibniz: 'A method of resolution ... [in which the geometers assume the unknown] and examine what follows from that assumption. If in this examination, they arrive at some clear truth from which the assumption follows necessarily, they conclude that the assumption is true.' Further stating that the unknown is to be represented by an abstract entity makes the method by definition model based. The abstract entity can be chosen from any domain which allows us to perform the operations which are part of the analytical method. Now, let us contrast the general definition of algebra with the following more specific one: 'Symbolic algebra is an analytical problem-solving method for arithmetical and geometrical problems consisting of systematic manipulation of a symbolic representation of the problem.' Here the definition specifically refers to a representation in the symbolic domain. As we claim that symbolic reasoning was a new development from the sixteenth century, the emergence of symbolic algebra is to be viewed as the transformation of algebra from the first to the second definition. This transformation process has been a long and very difficult one. Authors of algebraic works have been struggling with symbolism from the end of the fourteenth until the end of the sixteenth century. Such difficulties can be understood from the barrier theory by Margolis (1993). Habits of minds govern our cognitive processes and are similar to what Polanyi called 'tacit knowledge.' They can be considered critical intuitions within a community and are therefore constitutive of a paradigm. A barrier is an entrenched habit of mind that can block a cognitive breakthrough. Particular for symbolic thinking the conceptual barrier functions in two directions. The conceptual distance between the prevailing geometrical view of Arab algebra and the conflicting new ideas about symbolic reasoning determined the long historical process of difficulties. In the other direction, we are now so accustomed to symbolic reasoning that it becomes equally difficult to understand non-symbolic reasoning. In fact, many authors in the history of mathematics take symbolic reasoning so much for granted that they do not even notice the difference. By way of illustration we will look in detail at two interpretations of Babylonian algebra.

\section{Looking Behind Historical Barriers}

There was tremendous excitement on a conference on mathematical cuneiform texts in the late 1920s, when Otto Neugebauer announced that the Babylonians demonstrated knowledge for solving quadratic equations on clay tablets from about $1500 \mathrm{BC}$. This conference launched a two-decade hunt for and meticulous transcriptions of hundreds of new tablets, culminating in the seminal work of Neugebauer and Sachs (1945). Once and for all it was proven that solving equations is a human achievement which originated over 3,000 years ago. However, a recent publication by Høyrup (2002) completely overturns this view. Høyrup methodically and convincingly shows that his new interpretation of Babylonian algebra is a more 
appropriate one. By his simple methodological rule of 'close reading,' that one should also read the words and not only the numbers, he shows that the tablets explicitly talk about geometrical constructions rather than formulas or equations. Babylonians used a geometrical model to solve arithmetical problems in an analytic way. In contrast with Arab algebra, they did not use diagrams, and therefore the geometrical model was completely left unnoticed.

As an example let us look closer at tablet YBC 6967 from Yale University, written in the Akkadian dialect around 1500 BC. Concerning this problem Neugebauer writes the following ${ }^{2}$ :

The problem treated here belongs to a well known class of quadratic equations characterized by the terms igi and igi-bi (in Akkadian igüm and igibūm respectively) (...) We must here assume the product

$$
x y=60
$$

as the first condition to which the unknowns $x$ and $y$ are subject. The second condition is explicitly given as

$$
x-y=7
$$

From these two equations it follows that $x$ and $y$ can be found from

$$
x, y=\sqrt{\left(\frac{7}{2}\right)^{2}+60} \pm \frac{7}{2}
$$

a formula which is followed exactly by the text, leading to $x=12$ and $y=5$.

Important here is that Neugebauer claims that equations are 'explicitly given' and that the problem is 'found from a formula which is followed exactly by the text.' The English translation given by Neugebauer allows us to check these claims. For the 'explicitly given' equation we read 'The igibūm exceeds the igüm by 7.' This indeed corresponds with the Eq. 2. For the formula we read 'As for you-halve 7, by which the igibüm exceeded the igüm, and the result is 3.5. Multiply together 3.5 with 3.5 and the result is 12.25 . To 12.25, which resulted you, add 60 , the product and the result is 72.25 . What is the square root of 72.25: 8.5. Lay down 8.5, its equal and then subtract 3.5, the takilum, from the one, add it to the other. One is 12 , the other 5. 12 is the igibüm, 5 the igüm.' Again the text seems to correspond with the formula. There are two minor details here: the 'lay down' part sounds a little strange in this context, and Neugebauer adds 'we have refrained from translating takìlum,' because no sense could be given to it.

For Høyrup, the unknowns, igibūm and igüm, are represented by the sides of a rectangle (Høyrup 2002, 55-56). The term 'product' used by Neugebauer should be read as 'surface,' 'square root' as 'equal side' or the side of a square surface and adding means appending in length. Høyrup also gives an interpretation for the term takilum, which should be read as 'make-hold,' or making the sides of a rectangle hold each other. Only within a geometrical interpretation does it make sense to lay down something. Using a rectangle with sides igibūm and igūm, now everything fits together. The igibüm is 7 longer than the igüm. Cutting that part in half leads us to Fig. 1:

If we paste one of the halves below the rectangle at the length of the igum we obtain a figure with the same surface, equal to 60 (Fig. 2).

2 Neugebauer and Sachs (1945, 129-130). The Babylonians used the sexadecimal number system, in which the unit is represented by Neugebauer as 1,0 . We changed this to decimal numbers and added the reconstructed text fragments for easier reading, which leaves the problem text otherwise intact. 
Fig. 1 An example of the geometric algebra from the Babylonians

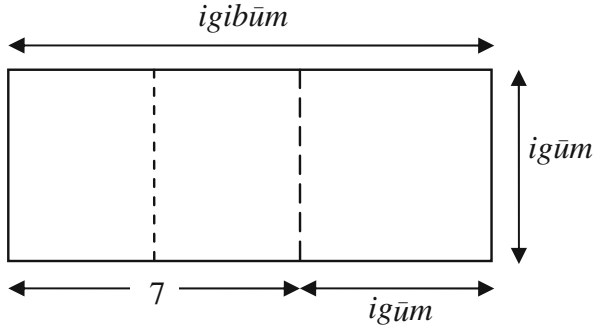

Fig. 2 Cut and paste method for solving quadratic problems

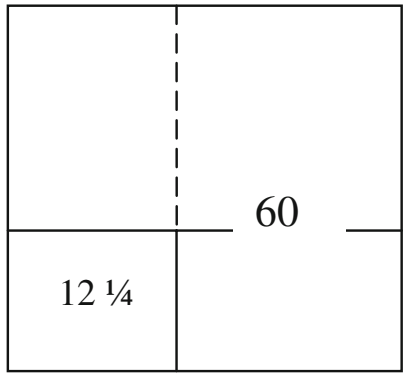

The part in the lower left corner must be a square, as its sides are both $3^{1} / 2$. We can thus determine its surface as $121 / 4$. The complete figure must also be a square with sides equal to igüm plus $31 / 2$. We know that the total surface is $721 / 4$, the 'equal side' of that square therefore is $81 / 4$. That leads us to a value of the igüm of 5 . Pasting the cut-out half back to its original place gives a length of the igibūm of 12 .

We are presented here with a completely different interpretation of that of Neugebauer. Høyrup accounts for anomalies in the standard interpretation and gives strong arguments for the reading of terms and actions in the geometrical sense. In this new interpretation there is no place for formulas. Babylonian algebra does not solve equations, as the concept of an equation was absent. But it fits our definition of algebra: the method is unquestionably analytical, it uses the unknowns igüm and igibūm and they are represented as abstract entities, namely the sides of a rectangle. We can also consider this to be a form of model-based reasoning as elementary geometry functions here as a model for solving arithmetical problems. In the rest of this paper we will consider the symbolic as a model for solving algebraic problems on the same par as geometry was for Babylonian and Arab algebra.

\section{The Concept of a Symbolic Equation}

The current consensus is that symbolic algebra originated with Viète at the end of the sixteenth century and is characterized by the study of the structure of equations rather than arithmetical problem solving by algebraic procedures (Mahoney 1980). In his Algebra, Viète (1591) introduced the use of the vowels A, E, I, O and $\mathrm{U}$ to represent unknowns, and the use of consonants for the constants and coefficients of an equation, as in $A^{3}+B^{2} A=B^{2} Z$. This was further adapted by Descartes in his Geometry of 1637 with the use of the last letters of the alphabet for unknowns and the first letters for constants and coefficients. This is basically the notation system we still use today. Little attention has been given in the literature to the influences that led to this system of symbolic representation. A notable exception is Cifoletti 
(1993). In our opinion, the road to symbolic algebra was paved by several previous stepping stones that have been functional in developing the symbolic mode of reasoning. The major obstacle in recognizing the importance of previous developments has been the confusion between the use of symbols and symbolic reasoning. As will be demonstrated below, several instances of symbolic reasoning in algebraic problem solving can be identified while no symbols are being used. To put it more strongly: symbols are introduced as a result of symbolic reasoning. Viète's study of the structure of equations and his introduction of symbolism was the result of the emergence of the concept of a symbolic equation during the sixteenth century.

In our project we looked behind the conceptual barrier and analyzed about thirty algebraic manuscripts and books written between 1460 and 1577 for methods and models in solving arithmetical problems. We approached the original texts from the viewpoint that the concept of an equation was not yet developed. In order to follow the problem-solving processes, we divided the original text in relevant fragments, accompanied by a meta-description in symbolic form. Our methodology of structural analysis follows that of Høyrup (2002) and further presupposes that a mathematical object can be considered to be present when firstly, it is consistently referred to within similar contexts, secondly, if it is acted upon by mathematical operations. We have looked in detail for the reference to and manipulation of unknowns and equations. We consider a symbolic mode of representation to be present when the metadescription corresponds to a reasonable degree with the actual text. According to these criteria the concept of an equation was completed in Buteo's Logistica of 1559. In summary, the six stages of development that have been functional for the process of concept formation are as follows:

1. The expansion of arithmetical operators to polynomials. A process of expansion has allowed to apply the operations of addition, subtraction, division and multiplication to other entities than natural numbers. This expansion process can be viewed both from the viewpoint of the objects as well as that of the operators. Arab algebra introduced operations on polynomial terms, which is clearly an expansion of the operator. Basic operations on numbers, such as addition or multiplication, were, in the fifteenth century, commonly applied to the sum of terms using one unknown: "1/3 von $6 \partial$ minner 300 ist 2 ding minder 100" $(6 \times-300$ divided by 3 is $2 \times-200)$ (Amann 1461, f.155 ${ }^{r}$ ). In his introduction to his Arithmetica, Cardano 1539 treats the operators one by one and discusses its application to whole numbers, fractions, irrationals and polynomial expressions. In this way, polynomials, which he calls de numeratione denominationem, can be viewed as an expansion of the number concept.

2. Equating polynomial expression. The very idea of an equation is based on the act of equating polynomial expressions. In fact, the Latin terms aequatio and aequationis refer to this action. Also the Sanskrit words samīcarana, samīcarā, or samīcriyā, used in Hindu algebra are often translated as 'equation.' The rationale for this is that sama means 'equal' and cri stands for 'to do.' However, we should be careful about interpreting these terms in the modern sense. They form an intermediate step in the emergence of the concept. Both in the literal and historical sense, it is in Cardano (1539) that we find the construction of an equation by equating polynomials (see Fig. 3).

3. Introduction of the second unknown. The importance of the use of multiple unknowns in the process leading to the concept of an equation cannot be overestimated. The very first instance in the western world can be attributed to the Florentine abacus master Antonio de' Mazzinghi, who wrote an algebraic treatise around 1380. The text is extant only from a witness account (Arrighi 1967). Maestro Antonio used two unknowns simultaneously to solve a single problem. The solution method was copied almost literally by Luca 


\section{6. p. .336 co. p. 144 ce. \\ $4 ; 56 . \overline{\mathrm{m}}, 2904 \mathrm{co} \cdot \overline{\mathrm{m}} .1452 \mathrm{ce}$. \\ $4160.2 q u a l i a\} 240$ co.p. 1596 ce.}

Fig. 3 Cardano's construction of an equation by equating polynomial expressions

Fig. 4 The first operation on an equation

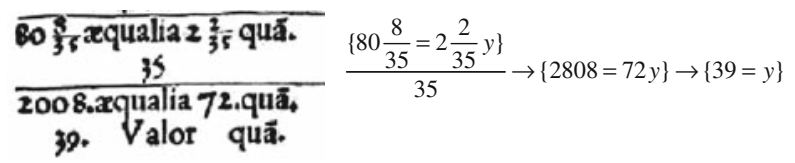

Pacioli in his Summa of 1494, and further discussed by Cardano both in his Arithmetica and the Ars Magna (Witmer 1968). The method was known in the early sixteenth century under the term regula quantitates.

4. Expansion of arithmetical operators to equations. Given an operational definition of the concept of an equation it is important to look for problem-solving methods which perform operations on an equation. The first explicit use of a multiplication of an equation is found in Cardano (1539, $\left.\mathrm{f} . \mathrm{HH} 1^{r}\right)$ where he uses two unknowns to solve a linear problem. Eliminating one unknown, he arrives at an equation, expressed in the second unknown, which he multiplies with 35, as shown in Fig. 4.

5. Introduction of letters for multiple unknowns. The use of letters to represent multiple unknowns was not an invention by Viète but originated in a book by Stifel (1544, f. $252^{r}$ ). Stifel uses the letters $A, B$ and $C$ and also proposes a notation for the powers and products of unknowns. However, Stifel $\left(1544\right.$, f. $\left.252^{r}\right)$ graciously acknowledges that he had obtained the idea from Christoff Rudolff and Cardano. For the square of B, Stifel uses the equivalent of $\mathrm{Bx}^{2}$ rather than $\mathrm{BB}$, while $\mathrm{x}^{2} \mathrm{~B}$ should be read as the product of $\mathrm{x}^{2}$ and B. The first to use the format AA for a square is Mennher (1556, $\mathrm{Qvi}^{r}-\mathrm{Qvi}^{v} ; 1565$, Ffviii $^{r}-$ Ffviii $^{v}$ ).

6. Systematic manipulation of linear equations to eliminate unknowns. The basic concept of a symbolic equation was completed by Buteo (1559) who not only performs operations on equations but also adds and subtracts two equations in a systematic way to solve a set of linear equations. In several problems solved by Buteo, the text corresponds very closely with our meta-description in modern symbolism. His method was further refined by Gosselin (1577) from which we know that he had some influence on Viète (Cifoletti 1993).

The concept of an equation was thus the result of a process that spans two centuries, exchanging the geometrical model with a symbolic one. The symbolic model allowed to solve arithmetical problems, making abstraction of the actual value or values of an indeterminate.

\section{The Acceptance of Symbolism}

Despite the accomplishments of sixteenth-century algebraists, it took many more years before the power of symbolic reasoning for arithmetic problems solving was fully acknowledged and accepted. In an influential algebra text book of the early seventeenth century by Clavius 
(1608) there is no use of multiple unknowns nor evidence of the advanced techniques of Buteo and Gosselin in solving linear problems. In fact, several publications show conceptual difficulties with some basic facts of symbolic reasoning which we now take for granted. Antoine Arnauld, who wrote an important philosophical work know as The Logic of PortRoyal (Arnauld 1662), also published a book on geometry (Arnauld 1667). There he gives an example of symbolic rules that he considers to be against our basic intuitions on magnitudes and proportions. His reasoning goes as follows. Suppose we have two numbers, a larger and a smaller one. The proportion of the larger to the smaller one should evidently be larger than the proportion of the smaller to the larger one. But if we use 1 as the larger number and -1 as the smaller one this would lead to $\frac{1}{-1}>\frac{-1}{1}$, which is against the rules of algebra. Witnessing the multiple instances in which this discussion turns up during the seventeenth century, the clash between symbolic reasoning and classic proportion theory, taught within the quadrivium, was experienced as problematic. Also Leibniz found it important enough to write an article about it (Leibniz 1712, 167). He acknowledges the problem as a genuine one, but states that the division should be performed as a symbolic calculation, the same way as we do with imaginary numbers. Indeed, when blindly applying the rules of signs there is no problem at all. When dividing a positive number by a negative one, the result is negative, and dividing a negative number by a positive one, the result is also negative. Therefore $\frac{1}{-1}=\frac{-1}{1}$. It is important to point out that these rules posed no problems in the abacus tradition before 1500. In the Summa, Pacioli lists the rules of signs for the arithmetical operations including division: 'A partire piu per meno nevē meno. A partire meno per piu nevē meno' (Pacioli 1494, f. 113 ${ }^{r}$ ). This shows that the symbolic way of reasoning to resolve the paradox, as proposed by Leibniz, was common practice in the abacus tradition. Although we do not find the symbols for division, negative numbers and equations in Pacioli or his predecessors, the common application of these operations provides evidence of a symbolic mode of reasoning. As pointed out by Leibniz, imaginary numbers can best be defined by listing the symbolic calculations that are possible on those objects. While Cardano still struggled with the interpretation of $\sqrt{-15}$, he was "putting aside the mental tortures involved" and performed the operation $(5+\sqrt{-15})(5-\sqrt{-15})$ correctly to arrive at $25+15$ (Cardano $1545,219)$. Bombelli later defined imaginary numbers by the eight combinatorial operations that are possible with the products of the negative and positive roots of plus and minus one. Note the correspondence with Pacioli's rules of sign when Bombelli gives: "Più [radice] di meno via più [radice] do meno fa meno" for $(\sqrt{-1})(\sqrt{-1})=-1$ or "Meno [radice] di meno via più [radice] do meno fa più" for $(-\sqrt{-1})(\sqrt{-1})=+1$ (Bombelli 1572, 169). These operations defined imaginary numbers within the symbolic model. The interpretation of its arithmetical equivalence still remained a mystery. Cardano (1663, VI, 373) later called it 'something of recondite nature' (natura abscondita). It took two more centuries to arrive at a geometrical interpretation of complex numbers.

\section{Interplay Between Object and Model}

Within the model-based reasoning framework, the interplay between the arithmetic on the object level and the model on the representational level is purposeful for the problem-solving process. The example given from Babylonian algebra shows how the cut-and-paste operations on the geometrical model are combined with operations from arithmetic to arrive at the values for the unknowns. After pasting back the cut-out halve, the length of the side of the rectangle can be determined by arithmetical addition. The problem-solving process switches between geometrical and arithmetical operations. Also the symbolic model cannot function 
on its own. The interplay between symbolic operations and arithmetical reasoning is crucial to avoid the trap falls of symbolic reasoning. An andequate example of possible dangers of blind manipulation of signs is one 'proof' from A budget of Paradoxes by De Morgan (1859). Take some time to notice where the problem is located:

$\begin{array}{lc}\text { Suppose we start from the identity } & x=1 \\ \text { multiplying each side with } x \text { gives } & x^{2}=x \\ \text { subtracting one leads to } & x^{2}-1=x-1 \\ \text { dividing by } x-1 \text { gives } & \frac{x^{2}-1}{x-1}=\frac{x-1}{x-1} \\ \text { splitting the square binomial gives } & \frac{(x-1)(x+1)}{x-1}=\frac{x-1}{x-1} \\ \text { which allows us to simplify as } & x+1=1 \\ \text { and this results in } & x=0\end{array}$

Although the rules of algebra have been applied correctly on the symbolic level, the fourth step was not allowed because we have divided by $x-1$ while $x$ had the value one. Division by zero leads to the contradictory conclusion of $x$ being equal to one as well as zero. However, the only way to avoid the mistake is to shift to the object level for a moment and to determine the value of the unknown. This shows that we cannot completely abandon the arithmetic behind the symbols. The liberating effect of the symbolic model is so strong that we might be led to conclude that operations on symbols is all that we need. This standpoint is advocated most strongly by the formalism of Hilbert. Within formalism the objects of mathematics are the signs themselves. Hilbert went so far as to state that: "I find the objects of the theory of numbers in the signs themselves, whose form we can recognize universally and surely, independently of place and time and the special conditions attending the production of the signs as well as of insignificant differences in their elaboration" (Hilbert 1922, 162). With 'insignificant differences in their elaboration' he seems to suggest that the ideas represented by the signs remain conserved throughout historical developments. But historical evidence precisely shows that significant shifts in the meaning of basic concepts leads to important developments such as that of symbolic algebra. Due to the interplay between the object level and the model, formalism is not the adequate framework to explain the function of symbolism. Let us look at some alternatives.

\section{Approaches to Symbolism}

What is so specific about symbolic reasoning? What makes symbolism so powerful that it has completely conquered mathematical and scientific discourse since the seventeenth century? Many philosophers, from Descartes and Leibniz to Peirce and Cassirer, have written extensively about the role of symbolism in mathematical problem solving. From the MBR point of view, we are interested in the way the symbolism contributes to the formation of new concepts in mathematics. As such, the role attributed to symbolic reasoning surpasses its problem-solving function. The symbolic not only allows us to solve mathematical problems with ease, it also functions in a creative way. Symbolism constitutes a mechanism for the creation of new concepts. One of the major contributions of Kant's Critique of PureRreason was to recognize the productive constructive function of concept formation. Mathematical concepts do not come from mere abstraction. They involve an act of free combination, or synthesis, as Kant called the process. He gives the example of a cone as 'the product of the arbitrary representation of a right-angled triangle which is rotated on one of its sides' 
(Kant 2:276; Walford 1992). Specific for symbolism, this act of synthesis is embedded in the signs used to represent the concept. The transcendental function of symbolism from Kant is further conferred by Cassirer (1957, vol. 3, 382):

Either the mathematical signs may be regarded as an end in themselves, as the actual objects of mathematical knowledge, or else some sort of intellectual life must be breathed into them; and it seems that this can be done only if we refer to something other, something outside themselves, and understand them as symbolic representations of this other. But once the road has been taken, once transient meaning is imputed to the figures of mathematics, no further limit seems to be imposed on thought: from transient meaning it is driven inexorably to transcendent meaning.

Conceding to a creative function of mathematical symbolism, and warned by Cassirer about the road to be taken, we would like to get a closer grip on the transcendental aspect. Cassirer remains rather vague about this and talks about "a peculiar and independent, self contained world of meaning according to an inherent formative law of its own," which gives the symbolic forms their special meaning (Cassirer 1957, 383). Symbolic forms thus represent mathematical objects but add something selfcontained, which we experience as creative and specific to concepts. What comprises this something extra? A highly original interpretation could be found in Foucault's archeology of the human sciences (Foucault 1966). Specifically alluring about Foucault's analysis is that his archeological approach is historical. Moreover, he situates an important historical transformation in symbolic representation in the sixteenth century. He analyses the basic human activities of representing, speaking, classifying and exchanging within the Renaissance context of mercantilism. This is the context in which we see the emergence of symbolic algebra. Foucault $(1966,29)$ calls the transformation process a superimposition of semiotics and hermeneutics. Hermeneutics is concerned with the discovery of the meaning of signs we use in language. Semiology, on the hand, attempts to define signs, and to discover how and by what laws signs are linked. According to Foucault, these two were superimposed during the sixteenth century. As an illustration he refers to the discussion on the symbolic function of signs in The Art of Thinking (Arnauld and Nicole, 1662). The classic theory of signs is based on a threefold relationship. You have the sign, which represents the signified, through a signifying theory. The signifying theory is necessary to link the symbol to the represented object and does so unequivocally. An evident example are religious symbols. Without knowledge of iconographical theory it becomes impossible to understand the reference to the sun and the moon by the monographs IHS and MA on medieval paintings, which stand for Jesus and Maria. However, in discussing the role of symbols during the seventeenth century Arnauld talks about a two-fold relationship: "the sign includes two ideas, one of the thing which represents, the other of the thing represented. Its nature consists of prompting the second by the first" (Arnauld 1996, 35). So how did the signifying theory disappear from the picture? It did not. The representative function became embedded in the sign. The nature of the symbol consists of prompting the signified by the sign. Therefore, the representational function merged with the symbol. According to Foucault, this made it impossible to have a theory of signs separate from an analysis of meaning. Foucault's analysis complements the transcendental function attributed to symbols by Cassirer. In a discussion on real and unreal elements in geometry, Cassirer specifically refers to a mechanism of embedding the representative function into the sign in the creation of new mathematical concepts (Cassirer 1957, 397):

Here again it is unnecessary to introduce the unreal elements as individuals leading some sort of mysterious existence side by side with the real points; the only logically and mathematically meaningful statement that can be made about them refers to the 
existence of relations that are embodied and expressed in them. But of course symbolic thinking of mathematics does not content itself simply with apprehending these relations in abstracto; it demands and creates a special sign for the logical and mathematical relationship that is present in them and ultimately treats the sign itself as a fully valid, legitimate, mathematical object.

Mathematical objects are thus created by the embodiment of their logical and mathematical relations which are represented in their sign. In the following we will apply this historical transformation of symbolism and the mechanism of embedding the representative function to the emergence of symbolic algebra.

\section{The Equality Symbol}

In a seminal work, Cajori gives a very comprehensive overview of the history and development of mathematical notations (Cajori 1928-1929). Cajori uses the terms sign, notation and symbol interchangeably and does not recognize the specific function of symbols. As a result of the appreciation of symbolism discussed above, we should be able to demonstrate the role in concept formation for some specific symbols. As a prime example let us look at the equality symbol. The equality sign evidently refers to the arithmetical equivalence of two expressions left and right from the sign. For example, the expression $3+5=8$ denotes the arithmetical equivalence of the sum of three and five with eight, as well as of eight with its partitioning into the numbers three and five. However, if we look at the historical moment in which the equality sign was introduced, we arrive at a very different picture. The equality sign as we now use it, was introduced in a book on algebra by Robert Recorde. He chose the sign of two parallel lines 'because no two things can be more equal.' This often quoted citation ignores the more important motivation for introducing the sign. Firstly, the equation sign was not introduced, either in his lengthy introduction, discussing the basic operations of arithmetic and extraction of roots, or in the dialogue on operations on polynomials or the rule of proportion. He introduced the sign in the chapter on the resolution of algebraic equations 'For easie alteration of equations ... And to avoid the tediouse repetition of these woordes: is equalle to: I will sette as I doe often in woorke use, a paire of parralle ... lines of one lengthe, thus : $==$, bicause noe 2 , thynges, can be moare equalle,' (Recorde 1557, $\mathrm{Ffi}^{\mathrm{V}}$ ). The use of the sign is thus specifically motivated by the alteration, or manipulation of equations. From this quote we can read the specific representational function that makes the equality sign a symbol of a new mathematical concept. In addition to its direct reference to arithmetical equivalence, the equality symbol also represents the combinatorial operations which are possible on an equation. These operations include adding or subtracting homogeneous terms on both sides of the equation, dividing or multiplying an equation by a constant or unknown (introduced by Cardano) and adding or subtracting two equations (introduced by Buteo). The equality sign symbolizes the algebraic equation. We have argued above that the concept of an equation fully emerged around 1560. We also stated that symbols are introduced as a result of symbolic thinking. The introduction of the equality symbol is historical evidence for the introduction of a symbol representing a newly emerged mathematical concept.

\section{The Metaphorical Basis of Symbolism}

If the symbolic can be considered a model for concept development and reasoning in arithmetic and algebra, one can ask what the metaphorical basis is for this model. Where did 
the symbolic model originate from? Why did symbolism become accepted in the sixteenth century? In search of a tentative answer, let us look at another development taking place in the same era and context. Consider the following statement. The emergence of double-entry bookkeeping by the end of the fifteenth century was a consequence of the transformation from the traveling to the sedentary merchant, primarily in the wool trade situated in Italy and Flanders. Given the vast body of evidence from Renaissance economic history and the evident causal relationship, not many will contest the connection between bookkeeping and merchant activities. What about the toned-down statement 'The emergence of symbolic algebra in the sixteenth century is to be situated within the socio-economic context of mercantilism.' Philosophers of mathematics who believe in an internal dynamics of mathematics will not accept decisive social influences as an explanation for the emergence of something as fundamental as symbolic algebra. At best, they will accept social factors in the acceleration or impediment of what they consider to be a necessary step in the development of mathematics. Also it seems difficult to pinpoint direct causal factors within economic history for explaining new developments in mathematics. However, the relationship between bookkeeping and symbolic algebra is quite remarkable. Many authors who have published about bookkeeping also wrote on algebra. The most notorious example is Pacioli's Summa, which deals with algebra as well as bookkeeping, and the book had an important influence in both domains. But there are more. Grammateus (1518) gives an early treatment of algebra together with bookkeeping. The Flemish reckoning master Mennher published books on both subjects including one treating both in the same volume (1565). So did Petri (1583) in Dutch. Simon Stevin wrote an influential book on algebra (1585) and was a practicing bookkeeper who wrote a manual on the subject (1608). In Antwerp, Mellema published a book on algebra (1586) as well as on bookkeeping (1590). While there is no direct relationship between algebra and bookkeeping, the teaching of the subjects and the books published often addressed the same audience. Children of merchants were sent to reckoning schools (in Flanders and Germany) or abacus schools (in Italy) where they learned the skills useful for trade and commerce. There is probably no need for algebra in performing bookkeeping operations but some basic knowledge of algebraic rules was very useful in complex bartering operations or the calculation of compound interest. In an important study on the Florence mercantile context, in which a surprisingly large body of algebraic manuscripts originated, Van Egmond (1976, p. 67) concludes: "The abaci are, in brief, one of the products of the commercial revolution and the culture of sedentary merchants." Given that these abaci produced over two hundred treatises on algebra, some of quite sophisticated nature, the stated relationship between mercantilism and symbolic algebra becomes more credible.

Finally, we would like to go one step further and rather than pointing out circumstantial factors that connect symbolic algebra with mercantilism, we are looking for direct influences for the transformation of symbolic thinking. Again, Foucault provides some important clues which we will apply to the influence of mercantilism on algebra. The first he calls the creation of value (Foucault 1966, 188). An essential aspect for the process of exchange in the Renaissance is the representation of value. 'In order that one thing can represent another in exchange, they must both exist as bearers of value; and yet value exists only within the representation (actual or possible), that is, within the exchange or the exchangeability.' The act of exchanging, i.e. the basic operation of merchant activity, both determines and represents the value of goods. To be able to exchange goods, merchants have to create a symbolic representation of the value of their goods. All merchants involved must agree about this common model to complete a successful transaction. As such, commercial trade can be considered a model-based activity. Given the current global financial market and the universal commensurability of money we take for granted, we pass over the common symbolic representation as 
an essential aspect of trade. However, during the Renaissance, the value of money depended on the coinage and the precious metals contained in them. These differed between cities, and their comparison varied in time. Furthermore, exchange by barter did not involve money and could include several parties from different cities or countries. Exchange was therefore a difficult operation with a serious risk of misevaluation. There is ample evidence that algebra was used in assisting in the quantification of value. Especially in the early sixteenth century, separate sections in algebra books were devoted to bartering (e.g. Vanden Houcke 1537, f. $156^{\mathrm{V}}-159^{r}$ ). We believe that the influence worked in both directions and that the creation of the symbolic representation of value also contributed to the development of symbolic algebra.

Foucault also points to the symbolic function of money as a result of mercantilism (Foucault 1966, 174). Apart from the intrinsic value of the metals that functioned to measure and substitute the value of goods, money was given an additional symbolic function. The symbolic function of money referred to its reciprocity with wealth. 'Wealth has the power to be exchanged; to analyze itself into elements that authorize relations of equality and inequality; to signify itself by means of those completely comparable elements of wealth called precious metals' (Foucault 1966, 179). As the actions and reciprocal relations of merchants, such as exchange, allegation of metals and bookkeeping became the basis for the symbolic and abstract function of money, so did the operations and the act of equating polynomials lead to the abstract concept of the symbolic equation. Both processes are model-based and use the symbolic as the model. Both involved a mechanism of embedding the representative function into the sign to create the modern conception of symbol.

Acknowledgements This paper results from a research project G.0193.04, from the Flemish fund for scientific research (FWO Vlaanderen). I would like to thank Michel Vandenbroeck for introducing me to Foucault (1966).

\section{References}

Amann, F. (1461). Deutsche algebra. Codex Latinus Monacensis 14908.

Arnauld, A., \& Nicole, P. (1662). La logique, ou, L'art de penser contenant, outre les re 'gles communes, plusieurs observations nouvelles propres a' former le jugement. Paris: Charles Savreux (English translation by Vance Buroker, J. (Ed.). (1996). Logic, or the art of thinking. Cambridge: Cambridge University Press).

Arrighi, G. (1967). Antonio de' Mazzinghi. Trattato di Fioretti, secondo la lezionedel codice L.IV.21 (sec. XV) della Biblioteca degli Intronati di Siena. Domus Galilaeana, Pisa: A cura e con introduzione di G. Arrighi.

Bombelli, R. (1572). L'algebra: parte maggiore dell'arimetica: divisa in tre libri. Bologna: Giovanni Rossi.

Buteo, J. (1559). Logistica. Lyon: Gulielmum Rovillium.

Cajori, F. (1928-1929). A history of mathematical notations (2 Vols.). La Salle, IL: Open Court Publishing Co.; reprinted by Dover, 1993.

Cardano, G. (1539). Practica Arithmetice. Milan: Bernardini Calusci.

Cardano, G. (1545). Ars Magna. Nürnberg: Johann Petreius. (English translation by Witmer, R. T. (1968). Ars Magna or the rules of algebra. Cambridge, Mass: M.I.T. Press; Reprinted by Dover Publications, New York, 1993).

Cardano, G. (1663). Opera omnia, (10 Vols.). Lyon: Jean Antoine Huguetan and Marc Antione Ravaud.

Cassirer, E. (1957). The philosophy of symbolic forms (3 Vols.). New Haven, Co.: Yale University Press.

Cifoletti, G. C. (1993). Mathematics and rhetoric. Jacques Peletier, Guillaume Gosselin and the making of the French algebraic Tradition. Ph.D. thesis, Princeton University, UMI Dissertation Services, Ann Arbor, MI.

Clavius, C. (1608). Algebra. Rome: Bartholomeus Zannetti.

De Morgan, A. (1859). A budget of paradoxes, London: Longmans, Green and co.

Descartes, R. (1637). Discours de la me'thode pour bien conduire sa raison \& chercher la varite' dans les sciences plus la diotrique, les meteores, et la geometrie, qui sont des essais de cete methode. Leyden: Ian Marie. 
Foucault, M. (1966). Les mots et les choses. Une arche'ologie des sciences humaines. Paris: Gallimard (English translation, 1971, The order of things: An archaeology of the human sciences. New York: Pantheon Books).

Gosselin, G. (1577). De arte magna, seu de occulta parte numerorum, quae \& algebra, \& almucabala vulgo dicitur, libri quatvor. Paris: Aegidium Beys.

Grammateus, H. (1518). Ayn new kunstlich Buech welches gar gewiss vnd behend lernet nach der gemainen Regel Detre, welschen practic, Reglen falsi vñ etlichäe Regeln Cosse. Nürnberg: Johannem Stüchs.

Hilbert, D. (1922). Neubegründung der Mathematik (republished in 1964, Hilbertiana: fünf Aufsätze. Darmstadt: Wissenschaftliche Buchgesellschaft).

Høyrup, J. (2002). Lengths, widths, surfaces: A portrait of old babylonian algebra and its kin. Heidelberg: Springer.

Leibniz, G. W. (1712). Observatio, quod rationes sive proportiones non habeant locum circa quantitates nihilo minores, \& de vero sensu methodi infinitesimalis. Acta eruditorum, pp. 167-169.

Mahoney, M. S. (1980). The beginnings of algebraic thought in the seventeenth century. In S. Gaukroger (Ed.), Descartes: Philosophy, mathematics and physics. Sussex: The Harvester Press, Chap. 5.

Margolis, H. (1993). Paradigms \& barriers: How habits of mind govern scientific beliefs. Chicago: University of Chicago Press.

Mellema, E. E. L. (1586). Second volume de l'Arithmetique. Antwerp: Gillis vanden Rade.

Mellema, E. E. L. (1590). Boeckhouder na de conste van Italien. Amsterdam: Gielis Van den Rade.

Mennher, V. (1556). Artithmétique seconde. Antwerp: Jan van der Loö.

Mennher, V. (1565). Practicque pour brievement apprendre à ciffrer, \& tenir livre de comptes auec la reg 'le de Coss, \& ge'ometrie. Antwerpen: Gillis Coppens van Diest.

Nesselmann, G. H. F. (1842). Die Algebra der Griechen nach den Quellen bearbeitet. Berlin: G. Reimer.

Neugebauer, O., \& Sachs, A. (1945). Mathematical Cuneiform Texts. American Oriental Society.

Pacioli, L. (1494). Summa de arithmetica geometria proportioni: et proportionalita. Continetia de tutta lopera. Venice: Paganino de Paganini.

Petri, N. (1583). Practicque, om te leeren rekenen, cijpheren ende boeckhouwen, met die regel coss ende geometrie seer profijtelijcken voor alle coopluyden. Amsterdam: Cornelis Claesz.

Recorde, R. (1557). The whetstone of witte whiche is the seconde parte of Arithmetike: containyng thextraction of rootes: the cossike practise, with the rule of equation: and the woorkes of surde nombers. Though many stones doe beare greate price, the whetstone is for exersice ... and to your self be not vnkinde. London: By Ihon Kyngston.

Stevin, S. (1585). L'Arithmetique. Leyden: Christophe Plantin.

Stevin, S. (1608). Livre de compte de prince a' la manie 're d'Italie: en domaine et finance extraordinaire. Leyden: Jan Paedts Jacobsz.

Stifel, M. (1544). Arithmetica integra. Nürnberg: Johann Petreius.

Vanden Houcke, G. (1537). Een sonderlinghe boeck in dye edel conste Arithmetica. Antwerp: Symon Cock.

Van Egmond, W. (1976). The commercial revolution and the beginnings of western mathematics in Renaissance Florence, 1300-1500. Ph.D. Thesis, Indiana University, Xerox University Microfilms, Ann Arbor, MI.

Viète, F. (1591). In artem analyticam isagoge. Seorsim excussa ab Opere restituae mathematicae analyseos, seu algebra nova. Tournon: J. Mettayer.

Walford, D. (Ed.). (1992). Theoretical philosophy, 1755-1770. The Cambridge edition of the works of immanuel Kant. Cambridge: Cambridge University Press.

Witmer, R. T. (1968). Ars Magna or the rules of algebra. Cambridge, MA: M.I.T. Press; reprinted by Dover Publications, New York, 1993.

\section{Author Biography}

Albrecht Heeffer holds a degree in Electronic Engineering and a $\mathrm{PhD}$ in philosophy from Ghent University. He is Fellow of the Research Foundation Flanders (FWO) and affiliated with the Center of Logic and Philosophy of Science at Ghent University, Belgium. Dr. Heeffer published on the history of optics and recreational mathematics and his main interest is a cross-cultural historical study of symbolic algebra. He is currently visiting researcher at Kobe University in Japan. Some recent publication include: "The Tacit Appropriation of Hindu Algebra in Renaissance Practical Arithmetic", Ganita Bharati, vol. 29, 1-2, 2007, pp. 1-60, and "A Conceptual Analysis of Early Arabic Algebra" in T. Street, S. Rahman and H. Tahiri (eds.) The Unity of Science in the Arabic Tradition: Science, Logic Epistemology and their Interactions, Springer, Dordrecht, 2008, pp. 89-129. 